\title{
BREVES CONSIDERAÇÕES SOBRE A NATUREZA JURÍDICA DA MEDIAÇÃO EXTRAJUDICIAL DE CONFLITOS ${ }^{1}$
}

\section{BRIEF CONSIDERATIONS ON THE LEGAL NATURE OF EXTRAJUDICIAL MEDIATION OF CONFLICTS}

Luis Daniel Alves Lima

Graduado e mestrando em Direito pelo UNICAP. Recife/PE. E-mail: daniel_de_lima@hotmail.com

Sergio Torres Teixeira Doutor em Direito. Professor da FDR/UFPE e UNICAP. Desembargador do TRT6. Recife/PE. E-mail: sergiotteixeira@uol.com.br

RESUMO: Qual a natureza jurídica da mediação extrajudicial de conflitos? O artigo tem por objetivo trazer um breve esclarecimento sobre este questionamento. Para isso, será realizada uma revisão de literatura e análise legislativa com o objetivo de apresentar os conceitos gerais das teorias concernentes à mediação extrajudicial e aos negócios jurídicos. Será utilizado o raciocínio dedutivo, adotando-se, como marco teórico, a Teoria do Fato Jurídico proposta por Francisco Cavalcanti Pontes de Miranda mais a Teoria dos Atos Performativos de Jonh Austin. Decorrente dessa análise, constatou-se que a mediação extrajudicial de conflitos é espécie de negócio jurídico pré-processual com possíveis efeitos processuais.

PALAVRAS-CHAVE: Mediação Extrajudicial de Conflitos. Resolução de Disputas Negócio Jurídico. Atos Performativos. Negócio Pré-processual.

\footnotetext{
${ }^{1}$ Artigo recebido em 16/07/2020 e aprovado em 15/11/2020.
} 


\begin{abstract}
What is the legal nature of extrajudicial conflict mediation? The article aims to provide a brief explanation of this question. For this, a literature review and legislative analysis will be carried out in order to present the general concepts of the theories concerning extrajudicial mediation and legal business. Deductive reasoning will be used, adopting, as a theoretical framework, the Theory of Legal Fact proposed by Francisco Cavalcanti Pontes de Miranda plus the Theory of Performative Acts by John Austin. As a result of this analysis, it was found that extrajudicial mediation of conflicts is a kind of preprocedural legal business with possible procedural effects.
\end{abstract}

KEY WORDS: Extrajudicial Mediation of Conflicts. Dispute Resolution. Juridic business. Performative Acts. Pre-procedural business.

\title{
1. Introdução
}

Sem dúvidas, em razão da busca pela solução do conflito de modo efetivo, nunca se valorizou tanto o instituto da mediação. Trata-se de um meio alternativo à jurisdição estatal para dissolução de controvérsias.

A experiência mostra que a resolução da discordância por meio da sentença judicial não responde mais às necessidades sociais de justiça. Por esse motivo, busca-se cada vez mais, por intermédio de políticas públicas, incentivar meios que tratem o conflito de forma distinta da jurisdição tradicional. A mediação, por exemplo, pode garantir aos mediandos o reestabelecimento da comunicação para melhor compreensão de suas questões sem impor uma decisão ${ }^{2}$. Por isso, no presente artigo, ela será abordada.

Em um primeiro momento, para o melhor entendimento do instituto, por intermédio da documentação direta, ou seja, da análise da resolução 125/2010 do Conselho Nacional de Justiça, a Lei $n^{\circ}$ 13.105/2015 (Código de Processo Civil de 2015) e a Lei $n^{\circ}$ 13.140/2015 (Lei da Mediação), será abordado, sem jornalismos teóricos, os tipos de mediação encontráveis na legislação pátria. Depois, com maior profundidade, mediante o

\footnotetext{
${ }^{2}$ KUNTZ, Tatiele Gisch.; PRIEBE, Victor. O papel da mediação e da conciliação na qualidade da jurisdição.
} Revista de Arbitragem e Mediação, v. 64, p. 237-255, 2020, p. 6 
uso da documentação indireta — pesquisa bibliográfica — será explicitado os conceitos da Teoria do Fato Jurídico nos moldes lecionado por Francisco Cavalcanti Pontes de Miranda no seu Tratado de Direito Privado, principalmente, mais as contribuições da Teoria dos Atos Performativos de Jonh Austin desenvolvida na sua obra "Quando dizer é fazer". Ambas são necessárias para a compreensão do tema ora apresentado. Para essa operação lógica, o modo de raciocínio utilizado será o dedutivo.

Embora já se tenha produzido bastante acerca do tema, desconhece-se pesquisa que aponte a substância jurídica acerca da mediação extrajudicial de conflitos. Por essa razão, essa pesquisa é de cunho exploratório, isto é, através dela, busca-se um novo ângulo dogmático para que futuros estudos possam ser realizados sob a perspectiva que será apresentada. Com ela, objetiva-se responder a seguinte questão: qual a natureza jurídica da mediação extrajudicial de conflitos? Logo, o objeto da pesquisa será a mediação extrajudicial de conflitos.

A perquirição dessa qualidade se justifica em razão do pouco material na literatura jurídica nacional a respeito do que se pode considerar processual ou não. Além disso, os seus resultados demonstram a necessidade do mediador saber qual o ramo do direito aplicável à mediação e quais são os seus institutos jurídicos, uma vez que conjunto de regras distintos acarretam diferentes modos de atuação do mediador. Além disso, os resultados dessa pesquisa servem para o aprimoramento do ensino da mediação nos diversos cursos jurídicos sobre o instituto. Por fim, o presente artigo ofertará uma reflexão acerca do papel do mediador em face dos mediandos.

Em um primeiro momento, através da revisão de literatura e da análise da legislação vigente, será abordado, sem jornalismos teóricos, os tipos de mediação encontráveis na legislação pátria.

Depois, com maior profundidade teórica, será explicitado os conceitos da Teoria do Fato Jurídico e dos atos performativos necessários para a compreensão do tema ora abordado. Para isso, será utilizado o raciocínio dedutivo.

Além do mais, sendo a mediação uma das diversas espécies de fatos jurídicos encontráveis no ordenamento jurídico, compreender as suas características requer do jurista, antes de tudo, o conhecimento da Teoria do Fato Jurídico proposta nos moldes 
lecionado por Pontes de Miranda juntamente com a teoria dos atos performativos de Jonh Austin, uma vez que a mediação é fato jurídico composto por atos performativos.

Embora se reconheça a importância dos contornos políticos, sociais e econômicos para o tema em comento, optou-se por observá-lo pela ótica da Teoria Geral do Direito, ou seja, como norma. Por esse motivo, o foco desse artigo será apresentar os conceitos lógicojurídicos referentes ao seu estudo como norma jurídica.

\section{A Mediação Extrajudicial}

Conforme dispõe o parágrafo único do artigo $1^{\circ}$ da Lei da Mediação (Lei $\mathrm{n}^{\circ}$ $13.140 / 2015)^{3}$, a mediação de conflitos é “a atividade técnica exercida por terceiro imparcial sem poder decisório, que, escolhido ou aceito pelas partes, as auxilia e estimula a identificar ou desenvolver soluções consensuais para a controvérsia." Significa dizer que ela é um meio de resolução de disputas parcial, ou seja, desenvolvida pelas próprias partes, uma vez que o terceiro - o mediador - auxilia a comunicação dos mediandos, apenas, para que esses possam compreender melhor as questões desacordantes entre si.

Logo, em razão da parcialidade destinada a esse modo de solução do conflito, a mediação pode se apresentar mais efetiva, dado que o mediador não possui qualquer poder decisório sobre a desavença dos indivíduos. A mediação extrajudicial, em suma, insere-se entre os meios alternativos de resolução de disputas parciais.

A mediação de conflitos se mostra vantajosa em face da jurisdição tradicional, pois: a) aos conflitantes é dado o poder de escolher um procedimento próprio para o seu desenvolvimento; b) existe a possibilidade da construção conjunta para solução da disputa sem a presença da perspectiva adversarial presente nos processos tradicionais; c) há o controle dos mediandos sobre o procedimento; d) a consensualidade é inerente a essa pratica; d) há diminuição do desgaste emocional dos envolvidos, a preservação da integridade física, moral, socioeconômica e sociológica dos conflitantes; e) e, por fim, é

\footnotetext{
${ }^{3}$ BRASIL. Lei no 13.140, de 26 de junho de 2015. Brasília, DF. Presidência da República Disponível em: < http://www.planalto.gov.br/ccivil_03/_Ato2015-2018/2015/Lei/L13140.htm >. Acesso em: 30 maio. 2020, às $10 \mathrm{~h}$.
} 
dada autoridade aos indivíduos para solucionarem suas questões de acordo com às suas necessidades ${ }^{4}$.

Em razão dessas vantagens, o Código de Processo Civil de 2015 (Lei n ${ }^{\circ}$ 13.105/2015) estabeleceu, na parte geral destinada as normas fundamentais, a promoção, sempre que possível, da solução consensual do conflito. Sendo a mediação um método de solução consensual do conflito, ela deve ser estimulada pelos juízes, advogados, defensores públicos e membros do Ministério Público, inclusive no curso do processo judicial ${ }^{5}$.

Além das vantagens pessoais da mediação, as grandes empresas, para evitar a morosidade da justiça estatal e os seus consequentes custos, cada vez mais, buscam o consenso para solucionarem os seus conflitos intersubjetivos, dado os baixos valores dispendidos nesses procedimentos. A mediação se mostra vantajosa para as grandes corporações, pois é dada a faculdade delas se utilizarem de um procedimento confidencial, flexível e mais célere que o ofertado pelo Estado. Por esse motivo, as empresas se valem da mediação em razão dos baixos custos em face da jurisdição estatal ${ }^{6}$.

O Conselho Nacional de Justiça, por exemplo, divulgou pesquisa informando que os processos extintos mediante sentença homologatória, ou seja, aqueles que passaram por algum tipo de procedimento de mediação ou conciliação duram menos que os processos que não tiveram esse tratamento. Esses processos tiveram uma menor quantidade de atos processuais. Os homologados encerram-se, em média, em 585 dias. Os não homologados em 1.109. Isto é, o processo encerrado mediante algum tipo de consenso das partes dura, mais ou menos, a metade do tempo do processo encerrado sem acordo. Dentre as conclusões apontadas pela pesquisa, observa-se que as matérias mais solucionadas mediante consenso são as bancárias e as pertinentes ao direito de familiar ${ }^{7}$. Logo, chega-se

\footnotetext{
${ }^{4}$ LIMA, Jean Carlos. Mediação de Conflitos. Teoria e Prática. Recife: Adsumus, 2017, p. 73-74

5. Art. $3^{\circ}$, § $3^{\circ}$. BRASIL. Lei $\mathbf{n}^{\mathbf{0}} \mathbf{1 3 . 1 0 5}$, de 16 de março de 2015. Código de Processo Civil. Brasília, DF: Presidência da República. Disponível em: <http://www.planalto.gov.br/ccivil_03/_ato20152018/2015/lei/113105.htm>. Acesso em: 30 maio. 2020, às 10h.

${ }^{6}$ LIMA, Jean Carlos. Mediação de Conflitos. Teoria e Prática. Recife: Adsumus, 2017, p. 49

7. BRASIL Conselho Nacional de Justiça. Mediação e conciliação avaliadas empiricamente: jurimetria para proposição de ações eficientes. Brasília, DF: Disponível em <https://www.google.com/url?sa=t\&rct=j\&q=\&esrc=s\&source=web\&cd=\&cad=rja\&uact=8\&ved=2ahUKE wjk2e6NuNnpAhVsH7kGHdTSBCEQFjADegQIAhAB\&url=https\%3A\%2F\%2Fwww.cnj.jus.br\%2Fdownlo ad\%2F3737\%2Fpesquisas-

judiciarias\%2F90915\%2Fsumarioexecutivo_usp.pdf\&usg=AOvVaw1V_srRk9vvAS15vA3LfFBu> Acesso em 29 maio 2020, p. 31-32
} 
à ilação de que grandes corporações financeiras estão dentre os litigantes que mais se utilizam dos métodos consensuais de solução do conflito.

Com o objetivo de identificar e distinguir a mediação da conciliação, o CPC/2015 esclarece que o mediador deve atuar preferencialmente nos casos em que já houver vínculo anterior entre as partes, auxiliando os conflitantes na compreensão das questões e nos interesses em conflito, de modo que eles possam, pelo restabelecimento da comunicação, identificar, por si próprios, soluções consensuais que gerem benefícios mútuos ${ }^{8}$.

$\mathrm{Na}$ conciliação, o conciliador atuará preferencialmente nos casos em que não houver vínculo anterior entre as partes, podendo sugerir soluções para o litígio, sendo vedada a utilização de qualquer tipo de constrangimento ou intimidação para que as partes conciliem ${ }^{9}$.

Portanto, conforme pode se destacar das leituras dos artigos, a distinção entre a conciliação e a mediação é mínima, embora ela exista. Em resumo, na mediação, o vínculo entre os conflitantes já existe, devendo o mediador agir como um comunicador, somente, restaurando o diálogo entre os mediandos. Sendo assim, não é dada a oportunidade de o mediador sugerir modos de solução para o conflito. Por outro lado, na conciliação, o vínculo, até então, era inexistente. Dessa forma, o conciliador poderá sugerir meios para solucionar o conflito existente.

Os ordenamentos jurídicos inserem a mediação por meio de duas vias: a judicial e a extrajudicial. Aquela ocorre em processo já instaurado, isto é, ocorrem dentro do próprio procedimento. Essa, por outro lado, acontece antes mesmo da apresentação da demanda ao Poder Judiciário ou, caso apresentada, em Câmara privada destinada para este fim. Desse modo, a mediação extrajudicial pode possuir natureza preventiva em relação ao processo contencioso ou resolutória do conflito. A verificação de sua essência deve ser observada pelo momento de sua suficiência: antes ou durante o processo. No caso da mediação

\footnotetext{
${ }^{8}$ Art. $165, \S 3^{\circ}$. BRASIL. Lei no 13.105, de 16 de março de 2015. Brasília, DF: Presidência da República. Código de Processo Civil. Disponível em: <http://www.planalto.gov.br/ccivil_03/_ato20152018/2015/lei/113105.htm>. Acesso em: 30 maio. 2020, às 10h.

${ }^{9}$ Art. $165, \S 2^{\circ}$. BRASIL. Lei $\mathbf{n}^{\mathbf{0}} \mathbf{1 3 . 1 0 5}$, de 16 de março de 2015. Código de Processo Civil. Brasília, DF: Presidência da República. Disponível em: <http://www.planalto.gov.br/ccivil_03/_ato20152018/2015/lei/113105.htm>. Acesso em: 30 maio. 2020, às 10h.
} 
decorrente antes da apresentação da demanda, busca-se o entendimento dos conflitantes antes mesmo da existência de um processo judicial ${ }^{10}$.

Em suma, com o intuito de evitar judicialmente o conflito, os contratantes podem inserir cláusulas de mediação antes da existência do processo, conforme dispõe o artigo $2^{\circ}$, $\S 1^{\circ}$ da Lei no 13.140/2015 (Lei de Mediação). Além disso, a qualquer tempo do processo, as partes poderão suspendê-lo para utilizar-se da mediação extrajudicial.

Por ser um procedimento voluntário dos envolvidos, elas possuem a autoridade para decidir e dispor sobre suas situações jurídicas. Assim, em face dessa possibilidade de disposição de objetos de direito, percebe-se a mediação extrajudicial como negócio jurídico, dado que, ao aceitarem a mediação para solucionar os seus conflitos, os envolvidos demonstram suas intenções de dispor suas situações jurídicas. No entanto, seria a mediação extrajudicial um negócio jurídico processual ou não?

O fato jurídico processual, conforme será visto adiante, é aquele que ocorre dentro de um procedimento jurisdicional. Desse modo, apesar da mediação ser um fato jurídico processualisado, ela não é processual. Pode-se afirmar, pois, que a mediação extrajudicial é um negócio jurídico pré-processual. Por essa razão, ele é regido pelas regras de direito material.

\section{Breves Considerações acerca da Teoria do Fato Jurídico}

Para se compreender a mediação extrajudicial como espécie de negócio jurídico pré-processual, faz-se necessário observar alguns conceitos construídos pela Teoria do Fato Jurídico. Por essa razão, nesse item será abordado a distinção entre mundo dos fatos e o mundo jurídico, a incidência da norma jurídica e o preceito legal dessas normas.

De acordo com Pontes de Miranda ${ }^{11}$, nem todos os fatos importam ao direito. Por essa razão, na sua teoria, existe o mundo dos fatos e o mundo jurídico. Ambos mundos formam o mundo geral, pois esse abarca a totalidade de fatos existentes nos dois mundos.

\footnotetext{
${ }^{10}$ ÁVILA, Eliedite Mattos. Mediação familiar judicial e extrajudicial. Revista dos Tribunais (São Paulo. Impresso), v. 101, p. 189-204, 2012, p. 2

${ }^{11}$ PONTES DE MIRANDA, Francisco Cavalcanti. Tratado de direito privado. v. 1. Campinas: Bookseller, 1999, p. 51.
} 
Desse modo, todos os fatos pertinentes a vida jurídica são configurados como suportes fáticos de regras jurídicas, ou seja, são os antecedentes descritivos das regras jurídicas. No entanto, a lógica das regras jurídicas requer necessariamente um prescritor, isto é, um preceito legal determinante das consequências jurídicas imputadas aquele fato previsto hipoteticamente. Por esse motivo, a lógica-jurídica representa uma relação de antecedente e consequente ${ }^{12-13}$.

Quando concretizado suficientemente no mundo sensível os elementos do suporte fático, a regra jurídica incide infalivelmente ${ }^{14}$. Dispensa-se, pois, qualquer atividade humana para a sua incidência. Por isso, para a sua teoria, a incidência se dá no mundo do pensamento ${ }^{15}$. A incidência, portanto, independe do conhecimento, vontade, anuência, adesão dos sujeitos. Por essa razão, distingue-se da aplicação da regra jurídica com a sua incidência, pois aquela é ato humano, e essa não ${ }^{16}$.

Para Adriano Soares da Costa, seguindo o pensamento ponteseano, a incidência não se dá no íntimo do sujeito cognoscente, pois “a norma jurídica que incide infalivelmente é a norma que ganhou em densidade simbólica, como fato do mundo social, no seu subconjunto, o mundo do pensamento ${ }^{17}$ ".

Para o jurista ponteseano ${ }^{18}$, o mundo do pensamento corresponde ao que Karl Popper denomina de "terceiro mundo". Existiria, por certo, um mundo material e um mundo mental. Não obstante, achar-se-ia um terceiro mundo distinto criado pelo homem, mas com realidade objetivável. Nesse mundo, passar-se-ia a incidência da regra jurídica, em face de sua objetividade independente do sujeito pensante. Logo, nota-se que

\footnotetext{
${ }^{12}$ MELLO, Marcos Bernardes de. Teoria do fato jurídico: plano da existência. 20. ed. São Paulo: Saraiva, 2014 , p. 53.

${ }^{13}$ LOURIVAL, Vilanova. Causalidade e relação no direito. 5. ed. São Paulo: Noeses, 2015, p. 85.

${ }^{14}$ PONTES DE MIRANDA, Francisco Cavalcanti. Tratado de direito privado. v. 1. Campinas: Bookseller, 1999 , p. 62.

${ }^{15}$ PONTES DE MIRANDA, Francisco Cavalcanti. Tratado de direito privado. v. 1. Campinas: Bookseller, 1999 , p. 62.

${ }^{16}$ PONTES DE MIRANDA, Francisco Cavalcanti. Tratado de direito privado. v. 1. Campinas: Bookseller, 1999 , p. 57

${ }^{17}$ COSTA, Adriano Soares da. Teoria da incidência da norma jurídica: crítica ao realismo linguístico de Paulo de Barros Carvalho. 2. ed. São Paulo: Malheiros Editores, [s.d.], p. 46

${ }^{18}$ COSTA, Adriano Soares da. Teoria da incidência da norma jurídica: crítica ao realismo linguístico de Paulo de Barros Carvalho. 2. ed. São Paulo: Malheiros Editores, [s.d.], p. 50
} 
pensamento pode ser compreendido no seu sentido subjetivo ou objetivo, sendo esse último o mundo apontado por Pontes de Miranda.

A mediação, de fato, mostra-se relevante ao direito. Por isso, em diversos ramos legislativo, ela é prevista hipoteticamente no suporte fático das normas jurídicas. Por essa razão, havendo vontade dos conflitantes em autocompor seus conflitos mediante a mediação, a norma jurídica incide sobre essa vontade conjunta, transformando esse fato do mundo em fato jurídico. A incidência dessa norma se dá de forma infalível, independentemente do querer dos indivíduos, cabendo aos mediandos aplicarem ou não conforme o previsto nas normas. Desse modo, explica-se o porquê das avenças celebradas durante a mediação surtirem efeitos jurídicos próprios, podendo, inclusive, serem eles exigidos judicialmente caso não sejam cumpridos pelos conflitantes. Com isso, completase a lógica antecedente/consequente das normas jurídicas. Isto é, a mediação é um fato jurídico.

\section{Da Mediação como Espécie de Negócio}

A compreensão da classificação da mediação extrajudicial como negócio jurídico pré-processual depende do entendimento de alguns elementos da teoria ponteseana. Por essa razão, para melhor compreensão do tema, explicar-se-á os critérios classificatórios do suporte fático e as diversas espécies de fatos jurídicos lícitos ${ }^{19}$. Depois, será avaliado os critérios distintivos entre o ato jurídico stricto sensu e o negócio jurídico com base no pensamento de Marcos Bernades de Mello e Adriano Soares da Costa, demonstrando, por fim, a mediação de conflitos como espécie de negócio jurídico.

Comumente, define-se o fato jurídico pela sua função ${ }^{20}$. O Código Civil de 1916, por exemplo, no seu art. 81 , conceituava o ato jurídico ${ }^{21}$ como "todo ato lícito que tenha

\footnotetext{
19 Por impertinência temática, neste artigo, não será analisado os fatos jurídicos ilícitos.

20 MELLO, Marcos Bernardes de. Teoria do fato jurídico: plano da existência. 20. ed. São Paulo: Saraiva, 2014, p. 164

21 O ato jurídico é uma das diversas hipóteses de fatos jurídicos, cabendo, pois, sua conceituação finalística ao conceito de fato jurídico.
} 
por fim imediato adquirir, resguardar, transferir, modificar ou extinguir direitos" 22 . Assim, o texto legal conceituava-o a partir de sua finalidade. Marcos Bernardes de Mello demonstra a impropriedade dessa atitude metodológica. Para o Mello ${ }^{23}$, "sendo a eficácia resultado do fato jurídico, não é conveniente definir a causa pela consequência, porque quando tivermos de definir a consequência (sic) teremos de nos reportar à causa e, assim, estará estabelecido um ciclo vicioso".

Por esse motivo, utiliza-se o conceito proposto por Pontes de Miranda. Para o autor, "fato jurídico é o que fica do suporte fáctico suficiente, quando a regra jurídica incide e porque incide" 24 . Desse modo, conforme fora abordado anteriormente, quando concretizado, no plano sensível da experiência, aquilo previsto hipoteticamente pela norma jurídica - fato ou complexo de fatos - ela incide, infalivelmente, colorindo o suporte fático, formando, assim, o mundo jurídico ${ }^{25}$.

Deve-se, portanto, evitar classificar as diversas espécies de fatos jurídicos existentes pelo seu efeito/fim. Inclusive, porque nem todos os fatos jurídicos dimanam, necessariamente, seus efeitos jurídicos $\operatorname{próprios}^{26}$. Diante disse, Mello ${ }^{27}$, seguindo os ensinamentos de Pontes de Miranda, propõe classificá-los segundo o elemento cerne do suporte fático, ou seja, o elemento constituidor de seu núcleo, buscando, pois, o dado essencial para a sua classificação. Em outras palavras, deve-se classificar o fato jurídico pelo seu elemento nuclear ${ }^{28}$.

\footnotetext{
22 BRASIL. Lei n 3.071, de $1^{\circ}$ de janeiro de 1916. Revogada pela Lei no 10.406, de 2002. Brasília, DF. Disponível em: http://www.planalto.gov.br/ccivil_03/LEIS/L3071.htm. Acesso em: 30 maio. 2020, às 10h. ${ }^{23}$ MELLO, Marcos Bernardes de. Teoria do fato jurídico: plano da existência. 20. ed. São Paulo: Saraiva, 2014, p. 164-165.

24 PONTES DE MIRANDA, Francisco Cavalcanti. Tratado de direito privado. v. 1. Campinas: Bookseller, 1999, p. 126.

${ }^{25}$ PONTES DE MIRANDA, Francisco Cavalcanti. Tratado de direito privado. v. 1. Campinas: Bookseller, 1999, p. 123-124.

${ }^{26}$ Por exemplo, o testamento revogado pelo autor. (MELLO, Marcos Bernardes de. Teoria do fato jurídico: plano da existência. 20. ed. São Paulo: Saraiva, 2014, p. 164).

${ }_{27}^{27}$ MELLO, Marcos Bernardes de. Teoria do fato jurídico: plano da existência. 20. ed. São Paulo: Saraiva, 2014, p. 170

28 COSTA, Adriano Soares da. Distinção entre o ato jurídico stricto sensu e negócio jurídico unilateral: breves anotações à margem de Pontes de Miranda. Revista de Direito Privado, v. 64, Ano 16, p. 105-115. São Paulo: Ed. RT, out.- dez. 2015, p.106
} 
Para tanto, observam-se dois grandes grupos de fatos jurídicos a partir dos seguintes critérios classificatórios para a análise do suporte fáctico: conformidade ou não do fato jurídico ao direito e a presença ou não de ato humano volitivo ${ }^{29}$.

Dentre os fatos lícitos há: (a) fatos jurídicos stricto sensu; (b) atos-fatos; (c) atos jurídicos lato sensu, subdividindo-os em (c.1) atos jurídicos stricto sensu; (c.2) negócios jurídicos.

$\mathrm{O}$ ato jurídico lato sensu subdividisse em ato jurídico stricto sensu e negócio jurídico. De acordo com Mello ${ }^{30}$, quando o direito concebe a vontade humana sem o poder de escolha da categoria jurídica, e com os seus efeitos pré-estabelecidos pelas regras jurídicas, estar-se-ia diante do denominado ato jurídico stricto sensu. Por outro lado, se a vontade dos figurantes da relação jurídica for recebida pelo ordenamento jurídico com o poder de escolha da categoria jurídica, podendo eles autorregrar os seus efeitos, o fato jurídico pertencerá à classe dos negócios jurídicos.

Em suma, o critério distintivo utilizado por Mello é o poder de escolha da categoria jurídica mais a possibilidade de autorregrar a vontade humana, propiciando, portanto, a possibilidade de estruturar o conteúdo da relação jurídica formada.

De certo modo, apesar de não deixar claro qual o critério utilizado para a correta diferenciação das espécies de atos jurídicos, a interpretação dada por Mello segue a lógica utilizada por Pontes de Miranda ao conceber a relação entre antecedente e consequente existente nos atos jurídicos stricto sensu e de escolha e escolhido, nos negócios jurídicos. No Tomo II do seu Tratado de Direito Privado ${ }^{31}$, por exemplo, leciona o autor:

\begin{abstract}
A distinção entre negócios jurídicos e atos jurídicos stricto sensu é assente na boa doutrina. Mas, quando se procura mostrar em que consiste a diferença, o mesmo engano e hábito, que levaram a definir-se o negócio jurídico pela escolha dos efeitos, conduz a caracterizá-la por serem, nos negócios jurídicos, resultante da vontade os efeitos e, nos atos jurídicos stricto sensu, da lei. No ato jurídico stricto sensu, a vontade é sem escolha da categoria jurídica, donde certa relação de antecedente a consequente, em vez de relação de escolha e escolhido.
\end{abstract}

\footnotetext{
${ }^{29}$ MELLO, Marcos Bernardes de. Teoria do fato jurídico: plano da existência. 20. ed. São Paulo: Saraiva, 2014, p. 170.

${ }^{30}$ MELLO, Marcos Bernardes de. Teoria do fato jurídico: plano da existência. 20. ed. São Paulo: Saraiva, 2014, p. 208-209.

31 PONTES DE MIRANDA, Francisco Cavalcanti. Tratado de direito privado. v. 2. São Paulo: Revista dos Tribunais, 2012, p. 536.
} 
No mesmo sentido, explica Adriano Soares da Costa ${ }^{32}$ que as diversas espécies de fatos jurídicos devem ser classificadas de acordo com o elemento núcleo do seu suporte fático. De acordo com o autor, a celeuma existente no trato das espécies de atos jurídicos lato sensu ocorre diante da existência dos negócios jurídicos unilaterais. Assim, verifica-se a dificuldade em distinguir os atos jurídicos stricto sensu dos negócios jurídicos unilaterais, pois ambos não se bilateralizam ${ }^{33}$.

Ademais, conforme apresenta Costa, apesar de Mello apreender bem o critério classificatório dos fatos jurídicos proposto por Pontes de Miranda, ele se equivoca ao utilizar como base distintiva das espécies de atos jurídicos o poder de escolha da categoria jurídica. Segundo Costa, essa opção adotada por Mello classifica os fatos jurídicos de acordo com os seus efeitos e não pelo núcleo de seu suporte fático. Por essa razão, o resultado da metodologia adotada por Mello se apresenta contraditória. Em suma, Mello entende que não deve se utilizar do critério finalístico, mas o utiliza, provavelmente, desapercebidamente.

Por fim, conforme visto, reforça-se mais uma vez que a conclusão demostrada por Mello se mostra inconveniente e deve ser repelida, pois o critério finalístico não explica o conteúdo das coisas, resultando, pois, na pouca informação a respeito do objeto cognoscível ${ }^{34}$.

Continuando seu raciocínio, Costa afirma existir negócios jurídicos unilaterais ${ }^{35}$ cujos efeitos são previamente predeterminados pelas regras jurídicas, não havendo, pois, a

32 COSTA, Adriano Soares da. Distinção entre o ato jurídico stricto sensu e negócio jurídico unilateral: breves anotações à margem de Pontes de Miranda. Revista de Direito Privado, v. 64, Ano 16, p. 105-115. São Paulo: Ed. RT, out.-dez. 2015, p. 108.

33 COSTA, Adriano Soares da. Distinção entre o ato jurídico stricto sensu e negócio jurídico unilateral: breves anotações à margem de Pontes de Miranda. Revista de Direito Privado, v. 64, Ano 16, p. 105-115. São Paulo: Ed. RT, out.-dez. 2015, p. 109

34 ABBOUD, Georges.; PEREIRA, Mateus Costa. O instrumentalismo processual à luz de críticas dogmáticas, filosóficas e epistemológicas: do não respondido ao irrespondível. In: Adriana Regina Barcellos Pegini; Daniel Brantes Ferreira; Diego Crevelin de Sousa; Evie Nogueira e Malafaia; Glauco Gumerato Ramos; Lúcio Delfino; Mateus Costa Pereira; Roberto Campos Gouveia Filho. (Org.). Processo e Liberdade: estudos em homenagem a Eduardo José da Fonseca Costa. 1ed. Maringá: Thoth, 2019, v. 1, p. $365-367$.

35 Para o autor, na derrelicção, espécie de negócio jurídico prevista no art. 1.276, § $2^{\circ}$ do Código Civil de 2002, não há qualquer poder de escolha da categoria jurídica, muito menos de seus efeitos. Nem por isso, deve-se classificá-lo como espécie de ato jurídico stricto sensu, uma vez que a vontade materialmente 
possibilidade de escolha da categoria jurídica nem dos seus respectivos efeitos. Desse modo, embaralhar-se-ia os critérios utilizados por Mello para a distinção entre os atos jurídicos stricto sensu e negócios jurídicos.

Assim, incube-se classificar as espécies de atos jurídicos de acordo com o cerne de seu suporte fático, isto é, a vontade. Para isso, com base na teoria dos atos de fala de Jonh Austin, Costa ${ }^{36}$ explica que, no universo dos atos jurídicos lato sensu, encontram-se duas espécies de vontade: declaração de vontade decisória/dispositiva ou apenas manifestação ou declaração de vontade assertórica. Para se identificar qual é o tipo de vontade nuclear manifestada lato sensu, deve-se observar a força ilocucionária dos atos de fala do figurante do ato.

Austin $^{37}$ afirma que, em certos proferimentos, quando se diz alguma coisa, estarse-ia fazendo algo. Em suma, às vezes, dizer é fazer. De acordo com ele, esses proferimentos seriam atos performativos. Para que isso ocorra, o proferimento não pode descrever, constatar, ser verdadeiro ou ser falso. Ademais, o proferimento da sentença deve ser, ao menos em parte, a realização de uma ação que não consiste unicamente em dizer qualquer coisa. Por essa razão, quando o noivo afirma que aceita aquela dama como sua esposa em uma cerimônia de casamento, ele não emite uma simples sentença, uma vez que não há possibilidade de se afirmar que ela é falsa ou verdadeira nem descritiva de algo. Ele está se casando, ou seja, fazendo algo. Por isso, quando o noivo profere o aceite, o seu dizer é um fazer, ou seja, nesse caso, um casar-se.

O mesmo ocorre no procedimento da mediação extrajudicial. Os envolvidos no conflito, ao aceitarem ou recusarem as propostas, não estão apenas declarando algo, mas sim fazendo. Estão realizando um acordo ou não. As suas sentenças, nesse caso, não passam pelo juízo de verdadeiro ou falso. Assim, a intenção da vontade é percebida na

exteriorizada possui força dispositiva. Nesse caso, por exemplo, dispõe-se do patrimônio abandonando-o. (COSTA, Adriano Soares da. Distinção entre o ato jurídico stricto sensu e negócio jurídico unilateral: breves anotações à margem de Pontes de Miranda. Revista de Direito Privado, v. 64, Ano 16, p. 105-115. São Paulo: Ed. RT, out.-dez. 2015, p. 109)

${ }^{36}$ COSTA, Adriano Soares da. Para uma teoria dos fatos jurídicos processuais. Revista de Processo, v. 270, p. 19-56. São Paulo: Revista dos Tribunais, 2017, p. 13

37 AUSTIN, Jonh Langshaw. Quando dizer é fazer. Trad. Danilo Marcondes de Souza Filho. Porto Alegre. Artes Médicas, 1990, p. 29 
possibilidade de disposição ou decisão autovinculante das situações jurídicas pertencente aos figurantes da mediação extrajudicial.

Em função disso, notando a peculiaridade dessas situações, Austin divide os atos performativos em locucionários, ilocucionários e perlocucionários ${ }^{38}$. Nos atos locucionários, profere-se enunciado para que o destinatário compreenda o que está sendo dito. Já nos atos ilocucionários, o locutor possui intenção de ordenar, criticar, perguntar, convidar. Em suma, seria o ato cujo qual o locutor exprime o que ele gostaria que fosse feito pelo interlocutor, ou seja, expressa uma intenção, observando as circunstâncias em que se usa as palavras ${ }^{39}$. Por último, os atos perlocurcionário exteriorizam os efeitos causados no interlocutor.

Buscando classificar os atos jurídicos lato sensu pela força ilocucionária, Adriano Soares da Costa perquiri a intenção da vontade do figurante ao manifestar/declarar algo, dividindo-a em vontade dispositiva/decisiva ou assertórica, conforme mencionado anteriormente. Havendo exteriorização de vontade dispositiva/decisiva, o sujeito de direito, por meio de sua intenção, expõe o seu objetivo sobre determinado objeto de direito ${ }^{40}$ pertencente a sua esfera jurídica. Por outro lado, na vontade exteriorizada assertórica, o manifestante lato sensu restringe-se a asserir ou registrar algo ocorrido. Tudo isso, frise-se bem, deve ser observado conforme o contexto da linguagem utilizada.

Por essa razão, ensina Costa que, nos atos jurídicos stricto sensu, a declaração de vontade não seria decisória, mas sim assertórica, pois haveria, somente, manifestação adeclarativa referente à comunicação de vontade, de fato, sentimento e enunciação assertórica em sentido débil, sendo, em vista disso, a força ilocucinária do ato de fala manifestante de algo sucedido no mundo sem força decisória ou dispositiva sobre esse algo.

\footnotetext{
38 CASTIN, Fernando. Jonh Austin e os atos de fala. Disponível em http://www.unicap.br/ojs/index.php/agora/ article/download/1004/865. Acesso em: 30 de jul de 2019, p. 8990.

${ }^{39}$ No mesmo sentido. (COSTA, Adriano Soares da. Para uma teoria dos fatos jurídicos processuais. Revista de Processo, v. 270, p. 19-56. São Paulo: Revista dos Tribunais, 2017, p. 12).

40 Objeto de direito é todo bem da vida distribuído pelas regras jurídicas atribuído a algum sujeito de direito. (MELLO, Marcos Bernardes de. Teoria do fato jurídico: plano da existência. 20. ed. São Paulo: Saraiva, 2014, p. 203).
} 
Por sua vez, nos negócios jurídicos unilaterais, a exteriorização de vontade se dá através da vontade dispositiva ou decisória ${ }^{41}$. Destarte, nos negócios jurídicos, há, efetivamente, disposição ou decisão sobre determinada situação jurídica pertencente ao seu figurante. Em regra, precisar-se-ia observar a linguagem e o modo que se quer falar para conceber corretamente a força ilocucionária dos atos de fala conteúdo da vontade do sujeito de direito.

Desse modo, percebe-se que a classificação dos atos jurídicos stricto sensu e o negócios jurídicos perpassa pela observação do uso da linguagem em seu contexto comunicacional. A intenção da vontade ditada pela força ilocucionária dos atos de fala pertence a esse mundo subjetivo objetivável, pois para se obter a intenção do locutor, devese utilizar a língua na relação eu-tu, ou seja, na relação simbolicamente construída socialmente atribuída aos signos linguísticos que ganha realidade própria do sujeito pensante. Em outras palavras, pensamento sem sujeito pensante, conforme já abordado.

Por fim, outro critério bastante útil para a distinção das espécies de atos jurídicos é a vinculatividade característica dos negócios jurídicos. A vontade negocial vincula o declarante, inclusive nos negócios jurídicos unilaterais ${ }^{42}$. De acordo com as lições de Pontes de Miranda ${ }^{43}$, a vinculatividade já é efeito de ato humano que entra no mundo jurídico. Caso o ato seja revogável, o efeito mínimo produzido será referente à vinculabilidade, pois o declarante poderá retirar a voz daquilo declarado. Por outra via, se for irrevogável, o efeito mínimo será a vinculação do ato, uma vez que a voz do emitente não poderá ser retirada. Por isso, nos negócios jurídicos, a manifestação negocial de vontade se dirige à vinculação, sempre ${ }^{44}$.

Nos atos jurídicos stricto sensu, não há o elemento autovinculativo. A ordem proferida não vincula o manifestante da vontade, apesar de ter de respeitá-la. Não houve,

\footnotetext{
${ }^{41}$ COSTA, Adriano Soares da. Distinção entre o ato jurídico stricto sensu e negócio jurídico unilateral: breves anotações à margem de Pontes de Miranda. Revista de Direito Privado, v. 64, Ano 16, p. 105-115. São Paulo: Ed. RT, out.- dez. 2015, p.112.

${ }^{42}$ COSTA, Adriano Soares da. Para uma teoria dos fatos jurídicos processuais. Revista de Processo, v. 270, p. 19-56. São Paulo: Revista dos Tribunais, 2017, p. 14-15.

${ }^{43}$ PONTES DE MIRANDA, Francisco Cavalcanti. Tratado de direito privado. v. 5. São Paulo: Revista dos Tribunais, 2012, p. 66.

${ }^{44}$ COSTA, Adriano Soares da. Para uma teoria dos fatos jurídicos processuais. Revista de Processo, v. 270, p. 19-56. São Paulo: Revista dos Tribunais, 2017, p. 15.
} 
aí, autorregramento da vontade. Ademais, o seu cerne não fora composto por vontade dispositiva ou decisória ${ }^{45}$.

Para se classificar a mediação de conflitos, deve-se, pois, observar o seu conteúdo, isto é, a vontade. A escolha pela mediação, por si só, demonstra a disposição de situação jurídica dos conflitantes referente à via judicial. Assim, abrem mão de acionar o Estado para a prestação jurisdicional que esse obrigara ${ }^{46}$ para, por vontade própria, resolverem suas desavenças com ajuda de terceiro. Por essa razão, a vontade núcleo do suporte fático da mediação mostra-se dispositiva/decisiva de situação jurídica. Assim, configura-se como espécie de negócio jurídico. No mais, as declarações de vontades produzidas dentro do procedimento da mediação vinculam os declarantes, sendo ela o efeito mínimo desse negócio jurídico, devendo os terceiros respeitarem-nas.

Contextualizando, imagine-se, hipoteticamente, por exemplo, que vizinhos estejam em conflito. $\mathrm{O}$ vizinho A é músico. $\mathrm{O}$ vizinho $\mathrm{B}$, por sua vez, possui um filho recém-nascido. Em razão do vizinho A trabalhar com música, ele precisa praticar uma quantidade de horas consideráveis por dia. Enquanto isso, o vizinho B necessita do silêncio para o descanso do seu filho. Em razão da boa convivência entre eles, ambos decidiram utilizar a mediação extrajudicial de conflitos para chegarem a um entendimento. No final do procedimento, acordaram que, enquanto o filho do vizinho B estivesse dormindo, o vizinho A não poderia praticar o seu instrumento. Por outro lado, o vizinho $\mathrm{B}$ teria de avisar sempre que o seu filho não estivesse descansando.

No exemplo trazido, observa-se que A e B deixaram de utilizar a jurisdição estatal para solucionarem o seu conflito mediante a mediação extrajudicial. Isto é, dispuseram de situação jurídica agregada às suas esferas jurídicas referente à obrigação do Estado em prestar a tutela jurisdicional em face do veto à justiça de mão própria. Essa decisão opera-

\footnotetext{
45 COSTA, Adriano Soares da. Para uma teoria dos fatos jurídicos processuais. Revista de Processo, v. 270, p. 19-56. São Paulo: Revista dos Tribunais, 2017, p. 15.

${ }^{46}$ Em razão do quase monopólio da justiça e o veto a autotutela, o Estado obrigou-se a prestar a tutela jurisdicional sempre que acionado, surgindo, pois, aos jurisdicionados a pretensão à tutela jurídica. Ela está prevista no art. $5^{\circ}$, inciso XXXV, da Constituição da República Federativa do Brasil Por esse motivo, considera-se essa pretensão uma situação jurídica de vantagem agregada a esfera jurídica dos cidadãos. Logo, ela pode ser disposta, em alguns casos, mediante a vontade dispositivas dos figurantes do ato, mediante a celebração de negócios jurídicos. PONTES DE MIRANDA, Francisco Cavalcanti. Tratado das ações. v. 1. São Paulo: Revista dos Tribunais, 2016, p. 278.
} 
se mediante a vontade de força ilocucionária. Assim, verifica-se que a composição suficiente para concretização do negócio jurídico referente à mediação.

As avenças produzidas pelos mediando são os efeitos de negócio jurídico, vinculando, pois, os declarantes as suas declarações como efeito mínimo dessa espécie de fato jurídico. Caso a mediação extrajudicial fosse ato jurídico stricto sensu, as partes não estariam vinculadas às suas declarações. Por essas razões, conclui-se que a mediação extrajudicial é um negócio jurídico.

\section{Elementos da Teoria do Fato Jurídico no Âmbito Processual}

Em concordância com as premissas teóricas assumidas até o presente, por se tratar de conceitos jurídicos fundamentais pertencentes à Teoria Geral do Direito, o estudo do fato jurídico é perfeitamente aplicável ao direito processual, observando-se, claramente, as especificidades inerentes ao trato da matéria.

Para conceituar o processo e, consequentemente, a decisão judicial, Fredie Didier $^{47}$ explica que o processo pode ser visto sob vários ângulos. O processo pode ser posto como meio de criação de norma jurídica, falando-se, assim, em processo legislativo.

Em sentido diverso, observando a Teoria do Fato Jurídico, concluir-se-á que o processo é ato jurídico complexo, diante da verificação da existência de um procedimento, isto é, um encadeamento de atos destinados a um fim.

Por último, em consonância com a teoria supracitada, o processo pode ser analisado sob a ótica eficacial dos fatos jurídicos. Processo, nessa linha de análise, seria o conjunto das diversas relações jurídicas existentes entre os sujeitos processuais presentes durante o interregno processual.

Conforme fora observado, processo como ato jurídico complexo é uma das possíveis abordagens para o estudo do tema. Observando-se a Teoria do Fato Jurídico, mais pormenorizadamente sob a ótica de seu plano existencial, chega-se à inferência que o processo é um conjunto de atos, conexos e consequentes, encadeados no tempo destinados

47 DIDIER JÚNIOR, Fredie. Teoria geral do processo, essa desconhecida. 4. ed. Salvador: Juspodivm, 2017 , p. 80 . 
Rio de Janeiro. Ano 15. Volume 22. Número 1. Janeiro a Abril de 2021

Periódico Quadrimestral da Pós-Graduação Stricto Sensu em Direito Processual da UERJ

Patrono: José Carlos Barbosa Moreira (in mem.). ISSN 1982-7636. pp. 545-567

www.redp.uerj.br

a um fim, qual seja a tutela jurisdicional ${ }^{48,49}$.

Mais precisamente, segundo as lições do jurista Adriano Soares da Costa, processo é a "sucessão de fatos jurídicos processuais concatenados em procedimento para obtenção da prestação jurisdicional" ${ }^{\text {50 }}$. A formulação utilizada por Costa se mostra mais eficiente para o estudo do tema, posto que inclui ao conceito de processo não somente os atos processuais, mas sim todas as espécies de fatos jurídicos processuais que podem se inserir no procedimento. Não obstante, faz alusão a prestação jurisdicional, uma vez que, para o autor, exista fatos processualizados e processuais, sendo este último espécie daquele.

Os fatos processualizados - gênero — ocorrem em ramos diversos do direito material $^{51}$. Por outro lado, o fato jurídico processual - espécie - gravita sobre a orbita da prestação jurisdicional oferecida pelo Estado. De modo semelhante, ensina Mello porque o conjunto de atos ordenados é sinônimo de procedimento: "Assim, pode-se chamar o conjunto de atos processuais de procedimento, sendo ele sinônimo de ato jurídico complexo, uma vez que se trata de atos provenientes de um mesmo poder ${ }^{52}$. De certo, o procedimento representa a organização e a disposição dos atos processuais previstas hipoteticamente nos suportes fácticos das regras jurídicas processuais ${ }^{53}$. Desse modo, explica Mello ${ }^{54}$ :

No ato complexo e no ato composto há um ato final, que o

48 DIDIER JÚNIOR, Fredie. Teoria geral do processo, essa desconhecida. 4. ed. Salvador: Juspodivm, 2017, p. 82.

${ }^{49}$ BRAGA, Paula Sarno. Norma de processo e norma de procedimento: o problema da repartição de competência legislativa no direito constitucional brasileiro. Salvador: Juspodivm. 2015, p.115

${ }^{50}$ COSTA, Adriano Soares da. Para uma teoria dos fatos jurídicos processuais. Revista de Processo, v. 270, p. 19-56. São Paulo: Revista dos Tribunais, 2017, p. 4

51 Por exemplo, direito tributário, administrativo. Há, inclusive, procedimentos nesses ramos do direito. Assim, o procedimento não é exclusivo do processo civil e do processo penal. (COSTA, Adriano Soares da. Para uma teoria dos fatos jurídicos processuais. Revista de Processo, v. 270, p. 19-56. São Paulo: Revista dos Tribunais, 2017, p. 2).

52 Para Marcos Bernardes de Mello, há uma diferença entre os atos complexos e os atos compostos. Na primeira espécie, os atos jurídicos procedem de um mesmo poder ou órgão administrativo. Contudo, os atos compostos originam-se de órgãos distintos, ou seja, de órgão que podem fazer parte de poderes diferentes. (MELLO, Marcos Bernardes de. Teoria do fato jurídico: plano da existência. 20. ed. São Paulo: Saraiva, 2014, p. 215-217).

53 ASSIS, Araken. Processo Civil Brasileiro: parte geral - fundamentos e distribuição de conflitos. v. 1, 1. ed. São Paulo: Revista dos Tribunais, 2015, p. 329.

${ }^{54}$ MELLO, Marcos Bernardes de. Teoria do fato jurídico: plano da existência. 20. ed. São Paulo: Saraiva, 2014, p. 216. 
caracteriza, define a sua natureza e lhe dá a denominação, e há atos condicionantes desse ato final, todos relacionados entre sim, ordenadamente no tempo, de modo que constituem partes integrantes de um processo, definido esse como um conjunto ordenado de atos destinados a certo fim.

Nesses termos, o autor deixa claro que fato jurídico processual é aquele que ocorre dentro do processo, ou seja, dentro do conjunto de fatos jurídicos dispostos em uma série procedimental destinados à prestação da tutela jurisdicional ofertada pelo EstadoJuiz, mesmo que algum de seus elementos se dê fora do processo.

A mediação extrajudicial não ocorre dentro de um procedimento direcionado à prestação jurisdicional. Por essa razão, não pode ser considerado negócio jurídico processual. No entanto, apesar de não ser um fato jurídico processual, os seus efeitos poderão modificar situações jurídicas processuais. Por exemplo, se o processo for suspenso por vontade das partes para realização da medição extrajudicial, a mediação ocorrerá fora do procedimento jurisdicional. O acordo das partes para suspender o processo é negócio jurídico processual, uma vez que ocorre dentro de um procedimento destinado à prestação jurisdicional. Por outro lado, a mediação que acontece fora desse processo é extrajudicial, embora os seus efeitos sejam percebidos dentro do processo ${ }^{55}$.

Como se deve evitar classificar os fatos jurídicos pelos seus efeitos, a mediação extrajudicial não é processual, mas sim pré-processual. Por essa razão, deve ser regida pelas regras de direito material. Logo, todos os pressupostos de existência, os requisitos de validade e os vícios do consentimento dos negócios jurídicos presentes na Parte Geral do Código Civil deverão ser observados para configuração da mediação extrajudicial sem quaisquer deficiências quanto aos seus efeitos jurídicos.

\section{Conclusões}

Em suma, percebe-se que o conteúdo formado nas exteriorizações de vontade dos sujeitos de direito envolvidos no procedimento da mediação extrajudicial consiste na

\footnotetext{
${ }^{55}$ A extinção do processo mediante sentença homologatória, por exemplo.
} 
intenção do figurante em dispor de situações jurídicas pertencentes às suas esferas jurídicas, ou seja, decidir sobre objetos de direitos seus.

Por essa razão, o fato jurídico, conteúdo da mediação extrajudicial, é o negócio jurídico pré-processual, uma vez que ocorre fora de um procedimento destinado à entrega da prestação jurisdicional. Assim, ele é regido pelas regras de direito material.

Apesar de não ser um fato jurídico processual, os efeitos da mediação podem alterar situações jurídicas processuais, dado que a mediação extrajudicial pode ocorrer em um processo já iniciado.

O benefício do presente artigo mostra-se mediante a conscientização do papel do mediador. Assim, sabendo ele que a mediação extrajudicial é regulada pelas normas de direito material, o mediador, caso seja necessário, deverá informar aos mediandos os limites lícitos, possíveis, determinados ou determináveis, por exemplo, das avenças celebradas em sede da mediação extrajudicial. Muitas vezes, os conflitantes desconhecem os termos jurídicos que envolve a mediação. Por isso, é de suma importância que os mediadores tenham domínio acerca dos pressupostos de existência e requisito de validade dos negócios jurídicos materiais.

Embora de suma importância, limitou-se, nessa pesquisa, a clarificação da natureza do negócio jurídico a partir de conceitos fundamentais com sede na Teoria do Direito. Por esse motivo, deixou-se de analisar - econômica, social, psicológica e pedagocimanete - a efetividade da mediação em relação à jurisdição estatal.

Sabendo-se, agora, da natureza jurídica da mediação extrajudicial de conflitos, poderão ser desenvolvidos outros estudos acerca do papel fiscalizatório do mediador, os efeitos da inclusão das matérias referente aos negócios jurídicos materiais no plano de aula para formação dos mediadores, os requisitos de validade da mediação para entes públicos, entre outros.

Em face do incentivo das políticas públicas destinadas aos meios alternativos de resolução de disputas, acredita-se que a presente pesquisa é de suma importância para os operadores do direito. Além disso, os resultados alcançados foram de importância teórica e prática para os presentes autores, uma vez que eles trabalham diretamente com a mediação 
extrajudicial de conflitos. Assim, puderam agregar conhecimento às suas atividades acadêmicas e profissionais.

\section{REFERÊNCIAS}

ABBOUD, Georges.; PEREIRA, Mateus Costa. O instrumentalismo processual à luz de críticas dogmáticas, filosóficas e epistemológicas: do não respondido ao irrespondível. In: Adriana Regina Barcellos Pegini; Daniel Brantes Ferreira; Diego Crevelin de Sousa; Evie Nogueira e Malafaia; Glauco Gumerato Ramos; Lúcio Delfino; Mateus Costa Pereira; Roberto Campos Gouveia Filho. (Org.). Processo e Liberdade: estudos em homenagem a Eduardo José da Fonseca Costa. 1ed. Maringá: Thoth, 2019, v. 1.

ASSIS, Araken. Processo Civil Brasileiro: parte geral - fundamentos e distribuição de conflitos. v. 1, 1. ed. São Paulo: Revista dos Tribunais, 2015.

AUSTIN, Jonh Langshaw. Quando dizer é fazer. Trad. Danilo Marcondes de Souza Filho. Porto Alegre. Artes Médicas, 1990.

ÁVILA, Eliedite Mattos. Mediação familiar judicial e extrajudicial. Revista dos Tribunais (São Paulo. Impresso), v. 101, p. 189-204, 2012

BRAGA, Paula Sarno. Norma de processo e norma de procedimento: o problema da repartição de competência legislativa no direito constitucional brasileiro. Salvador: Juspodivm. 2015.

BRASIL Conselho Nacional de Justiça. Mediação e conciliação avaliadas empiricamente: jurimetria para proposição de ações eficientes. Brasília, DF: Disponível em $<$ https://www.google.com/url?sa=t\&rct=j\&q=\&esrc=s\&source=web\&cd=\&cad=rja \&uact=8\&ved=2ahUKEwjk2e6NuNnpAhVsH7kGHdTSBCEQFjADegQIAhAB\&ur l=https $\% 3 \mathrm{~A} \% 2 \mathrm{~F} \% 2 \mathrm{Fwww} . c n j . j u s . b r \% 2 \mathrm{Fdownload} \% 2 \mathrm{~F} 3737 \% 2 \mathrm{Fpesquisas-}$ judiciarias\%2F90915\%2Fsumarioexecutivo_usp.pdf\&usg=AOvVaw1V_srRk9vvAS 15vA3LfFBu> Acesso em 29 maio 2020. 
BRASIL. Lei n 3.071, de $1^{\circ}$ de janeiro de 1916. Rio de Janeiro, RJ: Presidência da República. Revogada pela Lei $\mathrm{n}^{\mathrm{o}}$ 10.406, de 2002. Disponível em: <http://www.planalto.gov.br/ccivil_03/LEIS/L3071.htm>. Acesso em: 30 maio. 2020 .

BRASIL. Lei no 13.105, de 16 de março de 2015. Brasília, DF: Presidência da República. Código de Processo Civil. Disponível em: <http://www.planalto.gov.br/ccivil_03/_ato2015-2018/2015/lei/113105.htm>. Acesso em: 30 maio. 2020.

BRASIL. Lei no 13.140, de 26 de junho de 2015. Brasília, DF: Presidência da República Disponível em: <http://www.planalto.gov.br/ccivil_03/_Ato20152018/2015/Lei/L13140.htm>. Acesso em: 30 maio. 2020.

CASTIN, Fernando. Jonh Austin e os atos de fala. Disponível em http://www.unicap.br/ojs/index.php/agora/ article/download/1004/865. Acesso em: 30 de jul de 2019.

COSTA, Adriano Soares da. Distinção entre o ato jurídico stricto sensu e negócio jurídico unilateral: breves anotações à margem de Pontes de Miranda. Revista de Direito Privado, v. 64, Ano 16, p. 105-115. São Paulo: Ed. RT, out.-dez. 2015.

COSTA, Adriano Soares da. Para uma teoria dos fatos jurídicos processuais. Revista de Processo, v. 270, p. 19-56. São Paulo: Revista dos Tribunais, 2017.

COSTA, Adriano Soares da. Teoria da incidência da norma jurídica: crítica ao realismo linguístico de Paulo de Barros Carvalho. 2. ed. São Paulo: Malheiros Editores, [s.d.].

DIDIER JÚNIOR, Fredie. Teoria geral do processo, essa desconhecida. 4. ed. Salvador: Juspodivm, 2017.

KUNTZ, Tatiele Gisch.; PRIEBE, Victor. O papel da mediação e da conciliação na qualidade da jurisdição. Revista de Arbitragem e Mediação, v. 64, p. 237-255, 2020

LIMA, Jean Carlos. Mediação de Conflitos. Teoria e Prática. Recife: Adsumus, 2017.

LOURIVAL, Vilanova. Causalidade e relação no direito. 5. ed. São Paulo: Noeses, 2015. 
MELLO, Marcos Bernardes de. Teoria do fato jurídico: plano da existência. 20. ed. São Paulo: Saraiva, 2014.

PONTES DE MIRANDA, Francisco Cavalcanti. Tratado das ações. v. 1. São Paulo: Revista dos Tribunais, 2016.

PONTES DE MIRANDA, Francisco Cavalcanti. Tratado de direito privado. v. 1. Campinas: Bookseller, 1999.

PONTES DE MIRANDA, Francisco Cavalcanti. Tratado de direito privado. v. 3. São Paulo: Revista dos Tribunais, 2012.

PONTES DE MIRANDA, Francisco Cavalcanti. Tratado de direito privado. v. 1. Campinas: Bookseller, 1999.

PONTES DE MIRANDA, Francisco Cavalcanti. Tratado de direito privado. v. 5. São Paulo: Revista dos Tribunais, 2012. 